\author{
Marquette University \\ e-Publications@Marquette
}

College of Nursing Faculty Research and

Publications

Nursing, College of

7-2009

\title{
Predictors and Outcomes of Postpartum Mothers' Perceptions of Readiness for Discharge after Birth
}

Marianne E. Weiss

Marquette University, marianne.weiss@marquette.edu

Lisa Lokken

Wheaton Franciscan Healthcare-St.Joseph

Follow this and additional works at: https://epublications.marquette.edu/nursing_fac

Part of the Nursing Commons

\section{Recommended Citation}

Weiss, Marianne E. and Lokken, Lisa, "Predictors and Outcomes of Postpartum Mothers' Perceptions of Readiness for Discharge after Birth" (2009). College of Nursing Faculty Research and Publications. 34.

https://epublications.marquette.edu/nursing_fac/34 


\title{
Predictors and Outcomes of Postpartum Mothers' Perceptions of Readiness for Discharge after Birth
}

\author{
Authors: Marianne E. Weiss \& Lisa Lokken
}

\begin{abstract}
:
Objective: To identify predictors and outcomes of postpartum mothers' perceptions of their readiness for hospital discharge.

Design: A correlational design with path analyses was used to explore predictive relationships among transition theory-related variables.

Setting: Midwestern tertiary perinatal center.

Participants: One hundred and forty-one mixed-parity postpartum mothers who had experienced vaginal birth or Cesarean delivery of normal healthy infants.
\end{abstract}

Methods: Before hospital discharge, patients completed questionnaires about sociodemographic characteristics, hospitalization factors, quality of discharge teaching, and readiness for discharge. Three weeks postdischarge, mothers were contacted by telephone to collect coping difficulty and health care utilization data.

Main Outcome Measures: Readiness for Hospital Discharge Scale, Post-Discharge Coping Difficulty Scale, Utilization of postdischarge services.

Results: Quality of discharge teaching, specifically the relative difference in the amount of informational content needed and received and the skills of nurses in delivering discharge teaching, explained $38 \%$ of the variance in postpartum mothers' perceptions of discharge readiness. Readiness for discharge scores explained $22 \%$ of the variance in postdischarge coping difficulty scores. Nurses' skills in delivery of discharge teaching, coping difficulty, patient characteristics, and birth hospitalization factors were predictive of utilization of family support and postdischarge health care services.

Conclusion: A trajectory of influence was evident in the sequential relationships of quality of discharge teaching, readiness for discharge, postdischarge coping, and utilization of family support and health care services. Transitions theory provided a useful framework for conceptualizing and investigating the transition home after childbirth.

Readiness for postpartum discharge emerged as a national concern during the 1990s when length of hospital stay after childbirth markedly declined. Of concern was the mother's physical recovery from birth and the shortened learning trajectory. Passage of the Newborn and 1 Weiss \& Lokken 
Mothers Health Protection Act, 1996 (effective January 1, 1998), set the standards for postpartum hospital stay at lengths previously considered to be "early discharge." The decision to discharge is typically made by the medical team and often driven by utilization management efforts to meet payor criteria for length of stay. The amount of time available for discharge preparation is limited and insufficient to meet the learning needs of new mothers. The focus on immediate needs in the early postpartum period may not address the learning needs for postdischarge self and infant care (Bowman, 2005). Only a few studies of the transition home following birth have evaluated the mother's readiness for the challenges of self and family management at home following birth. The purpose of this study was to identify predictors and outcomes of postpartum mothers' perception of readiness for hospital discharge, specifically the role of discharge teaching provided by postpartum nurses to ready mothers for discharge, and the subsequent outcomes in the posthospitalization phase of the postpartum period.

\section{Background}

Childbirth and going home after birth mark important transition events in the lives of mothers, their newborns, and families. The postpartum period is a period of critical adjustment in personal well-being of the mother and child, psychosocial adjustments in the transition to parenthood, and new family dynamics. Criteria for discharge after childbirth reflect the recognition that preparation for self and infant care will promote a successful transition and healthy outcomes for mother and baby. The criteria proposed by the American Academy of Pediatrics and American College of Obstetricians and Gynecologists (2007) include: physiological stability; maternal knowledge, ability, and confidence in self-care and infant care; availability of support persons to assist in the initial transition period at home; and availability of continuing obstetric, infant, and nursing care following hospital discharge. Hospital-based postpartum care focuses on preparing parents with the knowledge and skills to successfully navigate the discharge transition.

While hospital discharge is an everyday occurrence in nursing practice, only two studies have focused on measurement of readiness for postpartum discharge. Bernstein et al. (2002) used a single item question to compare postpartum mothers' and pediatrician's assessments of discharge readiness. In this study of 55 mother-infant pairs, $20 \%$ were classified as unready if either the mother or the pediatrician did not feel it was the right day to be discharged. Agreement between mothers' and pediatricians' perceptions of discharge readiness exceeded $90 \%$ on the day of discharge but declined by 30\% 1 month later. Mothers were more likely to indicate lack of readiness than the pediatricians. Mothers who reported they were not ready for discharge also 
reported adverse postpartum outcomes, including being less happy, making twice as many phone calls to providers, and incorrectly placing the infant in a prone sleeping position.

Weiss, Ryan, and Lokken (2006) tested the reliability and validity of a 9-item Perceived Readiness for Discharge After Birth Scale. Reliability was supported. Validity testing using known groups' comparisons revealed that breast-feeding, married, and primiparous mothers reported less readiness for discharge than their respective comparison groups. The "personal status" subscale that measured the mothers' feelings of well-being on the day of discharge was predictive of self-reported physical and psychosocial problems and unscheduled utilization of health services in the first 6 weeks postpartum. The knowledge subscale was predictive of postdischarge telephone calls to the pediatric provider.

Teaching is the primary mechanism used by nurses to prepare patients and their families for discharge and the transition home (Titler \& Pettit, 1995). Research related to discharge teaching has focused on postpartum learning needs. Bowman's (2005) review of 18 studies of postpartum learning needs revealed an emphasis on differentiation of learning needs to be addressed during the postpartum hospital stay. Women and nurses identify immediate self and infant physical care needs as the priority for postpartum teaching (Beger \& Cook, 1998; Ruchala, 2000). Primiparas rate more topics as important to their learning needs than multiparas (Beger \& Cook). There were no studies that specifically addressed Cesarean mothers' postpartum informational needs of the discharge transition after childbirth. Discharge teaching should anticipate knowledge needed for postdischarge self-management because new learning needs continue to develop after hospital discharge (Sword \& Watt, 2005). The quality of discharge teaching and the impact on postdischarge outcomes has not been systematically investigated.

\section{Theoretical Framework}

Meleis' middle range theory of transitions (Meleis, Sawyer, Im, Messias, \& Schumacher, 2000) provided a framework of concepts that are relevant to the specific transitional situation of going home from the hospital after childbirth. The theory was used to guide identification of variables for this study. A transition is a process of passage from one life phase, condition, or status to another during which changes in health status, role relations, expectations, or abilities create a period of vulnerability (Meleis \& Trangenstein, 1994; Meleis et al., 2000). Hospital discharge was viewed as a transitional process occurring in three phases: (a) the hospitalization phase during which discharge preparation occurs, (b) the discharge when short-term outcomes of the preparatory process can be measured, and (c) the postdischarge period when patients'

3 Weiss \& Lokken 
perceptions of their ability to cope with the demands of care at home and their needs for support and assistance from family and health services provide evidence of positive or adverse outcomes of the postpartum woman's transitional process.

Transitions theory proposes that the nature of the transition, transition conditions, and nursing therapeutic practices will affect patterns of response during a transition. In this study the nature of the transition was represented by three "hospitalization factors" that account for the differences in birth hospitalization: (a) experiences due to previous admission for a birth experience (parity of the mother), (b) type of birth event (either vaginal or Cesarean), and (c) feeding method (breast or bottle). Patient characteristics represented the personal and environmental conditions that could facilitate or inhibit the transition process and included the mother's age, race/ethnicity, socioeconomic status, whether she was living with the father of the baby, and payor type. Discharge teaching was selected as the nursing therapeutic process to be investigated as a predictor of discharge readiness, which represented a pattern of response during the transition. Postdischarge coping difficulty and utilization of health services were included as end-outcome patterns of response.

\section{Methods}

The following research questions guided the study:

1. What patient characteristics, birth hospitalization factors, and hospital nursing practices are predictive of postpartum mothers' perceptions of readiness for hospital discharge following birth?

2. Do postpartum mothers' perceptions of readiness for discharge following birth predict postdischarge coping difficulty and utilization of family support and health services?

This study was part of a three-study series investigating relationships between predictors and outcomes of readiness for hospital discharge conducted concurrently with three different groups of patients hospitalized in acute care facilities (adult medical surgical patients, postpartum mothers, and parents of hospitalized children; Weiss et al., 2007, 2008). The study reported here used a correlational design with variables specific to postpartum women.

The sample consisted of postpartum mothers at an urban tertiary-level perinatal center in the midwestern United States. To achieve the goal of sampling postpartum women experiencing uncomplicated birth events, patients were recruited during the postpartum hospital stay if they 4 Weiss \& Lokken 
met the study inclusion criteria: (1) at least 18 years of age, (2) uncomplicated postbirth experience evidenced by discharge home accompanied by the newborn within 4 days after birth, (3) sufficient English language skills to read and respond to consent forms and study questions, and (4) telephone access for postdischarge data collection. A sample size of 120 was estimated to achieve a power of at least $80 \%$ in multiple regression analyses with up to 10 predictor variables at a moderate effect size (Polit, 1996). A total of 141 patients enrolled in the study, 129 $(91.5 \%)$ completed data collection at discharge, and 131 (92.9\%) completed the 3 week postdischarge telephone interview. One hundred and nineteen patients (84.4\%) completed all data collection periods. The sample included women with singleton as well as 5 twin births who met the study inclusion criteria.

\section{Procedures}

University and participating hospital Institutional Review Board approvals were secured. Undergraduate nursing students who served as study research assistants (RAs) were trained by the principal investigator (M. E. W.) in the study procedures for screening for eligibility, obtaining informed consent, collecting and recording data, and telephone interviewing. During the postpartum hospitalization, the RAs reviewed inpatient hospital records to identify eligible patients, described the study to potential participants, obtained informed consent, and abstracted medical records. Within 2 hours before discharge, unit nursing staff provided the Readiness for Hospital Discharge Scale (RHDS) and the Quality of Discharge Teaching Scale (QDTS) in a study packet to be completed before discharge. The RA who enrolled the patient conducted a telephone interview at 3 weeks postdischarge to collect Post-Discharge Coping Difficulty Scale (PDCDS) and postdischarge utilization data.

\section{Variables and Instruments}

Patient Characteristics and Hospitalization Factors

During the postpartum hospitalization before discharge, data were collected on patient characteristics (age, race/ethnicity, socioeconomic status, living with father of the baby, and payor) and birth hospitalization factors (previous admission for a birth [primipara or multipara], type of birth [vaginal or Cesarean], feeding method). The Hollingshead 4 Factor Index of Social

Status was used to calculate a family socioeconomic status score from education and occupation data of one or both parents depending on marital status (Hollingshead, 1975).

Three scales were developed and tested for the concurrent studies of the three patient populations. The RHDS was a modification and extension of earlier work by Weiss et al. (2006) with postpartum patients. The QDTS and PDCDS were developed for the specific purposes of

\section{Weiss \& Lokken}


measuring variables related to the discharge transition. Descriptions of the development and testing of the instruments have been published. (Weiss \& Piacentine, 2006; Weiss et al., 2007, 2008)

\section{Readiness for Hospital Discharge}

The postpartum version of the RHDS was used to capture postpartum mothers' perceptions of readiness for discharge. The RHDS-New Mother Form is a 22-item instrument that includes 21 items from a master version of the RHDS that was developed for assessment of discharge readiness in patients discharged from acute care facilities. The items on the new mother form contain the same item content as the master version but are worded specifically for the postpartum mother. The items form four sub-scales: personal status, knowledge, coping ability, and expected support. The additional item is included in the personal status scale and requests that the mother rate her physical ability to care for her baby. The RHDS is a self-reported summated rating scale with items scored on an 11-point scale (0-10) with anchor words (e.g., not at all, totally) to cue the subject to the meaning of the numeric scale. Higher scores indicate greater readiness. The reading level of the instrument is a grade level of 7.3 (Microsoft Word 2003, Flesch-Kincaid Grade Level Score). Construct validity, using confirmatory factor analysis and contrasted group comparisons, and predictive validity were supported for the 21 -item scale (Weiss and Piacentine, 2006). The Cronbach's a reliability estimates were .92 for the 22 -item RHDS-New Mother form and .84, .82, .86, and .81 for the personal status, knowledge, coping ability, and expected support subscales, respectively.

\section{Discharge Teaching}

Educational preparation for discharge was measured using the QDTS (Weiss et al., 2007). Discharge teaching was conceptualized as the composite of all teaching received by a patient (from the patient's perspective) during the hospitalization in preparation for discharge home and coping with the posthospitalization period. Principal components exploratory factor analysis of the QDTS data for the combined studies sample identified a two-factor structure (content and delivery) accounting for $54.2 \%$ of scale variance (Weiss et al.). The QDTS-New Mother form consists of 19 items and uses a similar scaling format to the RHDS. The content subscale consists of 7 paired items representing the amount of "content needed" and "content received" during teaching in preparation for discharge. The 12-item "delivery" sub-scale reflects the skill of the nurses as educators in presenting discharge teaching and includes items about listening to and answering specific questions and concerns, expressing sensitivity to personal beliefs and values, teaching in a way that the patient could understand and at times that were good for patients and

\section{Weiss \& Lokken}


family members, providing consistent information, promoting confidence in ability to care for themselves and knowing what to do in an emergency, and decreasing anxiety about going home.

The total scale score is calculated by adding the content received and the delivery subscale scores. The Cronbach's a reliability coefficients for the postpartum mother sample were .87 for the total scale and .85 and .84 for the "content received" and "delivery" subscales, respectively. A "content difference" subscale can be generated by subtracting "content needed" from "content received" creating a score that reflects the amount of informational content received in excess of reported need. The "content difference" subscale can be used as an alternative to the "content received" subscale. The Cronbach's a for the "content difference" subscale was 88 .

\section{Postdischarge Coping Difficulty}

The 10-item PDCDS uses the same scaling format as the RHDS with higher scores representing greater coping difficulty. The new mother form of the PDCDS includes content domains consistent with the forms of the instrument used in other patient samples with wording modified for appropriateness to the postpartum mother's situation. Attributes of postdischarge coping that are included in PDCDS items are difficulties with stress, recovery, self-care, self and infant care management, family difficulty, help and emotional support needed, confidence in self-care and infant care management abilities, and adjustment. Exploratory factor analysis with the combined studies sample indicated a single dominant factor accounting for $39 \%$ of scale variance. Reliability for the postpartum sample was .74 .

Postdischarge Utilization of Support and Health Services

Utilization of support and health services was self-reported during a postdischarge telephone interview. The following occurrences were recorded in dichotomous format (yes/no): calls to friends and family for advice and/or support, calls to obstetric and pediatric providers, office or clinic visits, calls to the hospital for mother or infant problems, and urgent care/emergency room visits by the mother and newborn. Readmissions were recorded but not included in analyses due to the small number of occurrences.

\section{Analysis}

Path analyses of relationships described in the proposed study model based on transitions theory (Figure 1) were conducted using multiple regression for examining outcome variables measured at the interval level (RHDS and PDCDS) and logistic regression for outcome variables measured at the nominal level (utilization variables). For each of these three transition outcomes, regression models were tested for each of the transition theory groupings of predictor

7 Weiss \& Lokken 
variables (transition conditions, nature of the transition, nursing therapeutics). When multiple predictors were identified for an outcome, a final regression model was tested using only the significant predictor variables from the preliminary analyses. This procedure assisted with retention of statistical power.

\section{Results}

\section{Sample Characteristics}

The sample characteristics are presented in Table 1. The Hollingshead 4 Factor Index of Social Status score of 43 was greater than the scale's median value of 33 . These scores were consistent with the high percentage of mothers with postsecondary education (66\%). The race ethnicity distribution of the sample reflects the diversity of women in the urban location of the study site, although there were fewer Hispanic women than expected for the local demographics (http://dhs.wisconsin.gov/wish/).

Overall, $97 \%$ of patients reported being ready to go home on a single item dichotomous (yes/no) format question. Descriptive statistics for QDTS, RHDS, and PDCDS and frequency statistics for the postdischarge utilization variables are presented in Table 2. On average, the mothers in the sample reported that they received good quality teaching and were reasonably but not totally ready for discharge. The positive mean score on the content difference sub-scale of the QDTS indicated that these mothers perceived that they received more content than their stated need. Only 8 mothers $(6.6 \%)$ reported receiving less teaching than they felt they needed. The mothers reported low levels of difficulty coping in the postdischarge period. Utilization of friends and family for advice and support was prevalent in the first 3 weeks postdischarge. In that period, $41(31.3 \%)$ of the mothers contacted their obstetric provider either by telephone $(10.7 \%)$ or by office visit (20.6\%). For newborn care services, a total of $128(97.7 \%)$ mothers contacted the pediatric provider, $28.1 \%$ for telephone consultation and $70.2 \%$ visited the office or clinic.

\section{Research Question 1: Predictors of Readiness for Discharge}

The results of multiple regression analyses of the RHDS are presented in Table 3. The first path to be analyzed was the relationship of patient characteristics and RHDS. The five predictor variables were entered simultaneously into the regression equation (Table 3, Model 1). None were significant predictors of the mothers' perceptions of their readiness for discharge. The three hospitalization factors were entered simultaneously as predictors into a regression equation for RHDS (Table 3, Model 2). Again, none were significant predictors of RHDS.

The nursing therapeutics variable, QDTS, was then entered into a linear regression

\section{Weiss \& Lokken}


analysis as a predictor of RHDS (Table 3,Model 3a). The QDTS total scale score was a statistically significant predictor accounting for $15 \%\left(R^{2} .15\right)$ of the variance in RHDS scores. When the subscale scores of the QDTS (content "received" and "delivery") were substituted for the QDTS total score, only the "delivery" subscale contributed to the explained variance in RHDS (Table 3, model 3b). In a subsequent exploration substituting the "content difference" subscale for the content received subscale, content difference and delivery together explained $38 \%\left(R^{2}=.38\right)$ of the variance in RHDS for this study sample with a population estimate for a larger study sample of 37\% (adjusted $\mathrm{R}^{2}=.37$ ) (Table 3, model 3c). The direction of the relationships between the QDTS and RHDS was in the expected direction with quality ratings of discharge teaching on both subscales of the QDTS ("content difference" and "delivery") positively associated with mothers' readiness for discharge.

\section{Research Question 2: Readiness for Discharge as a Predictor of Postdischarge Outcomes}

The relationships of readiness for discharge to two postdischarge outcomes, postdischarge coping difficulty and utilization of support and health care services, were evaluated. The results of path analyses of predictors of PDCDS scores and utilization of services are presented in Tables 4 and 5 respectively.

Readiness for Hospital Discharge Scale was entered as a predictor in a linear regression equation for PDCDS as the outcome variable. The results (Table 4, Model 1) indicated that RHDS scores explained $22 \%$ of the variance in PDCDS scores. To assess the contribution of all variables temporally antecedent to postdischarge coping, multiple regression analyses were then computed for sets of predictor variables in their theory-based groupings: Model 2-transition conditions (patient characteristics); Model 3-nature of the transition (hospitalization factors); Model 4-nursing therapeutics (QDTS). A final model (Model 5) was computed with all significant predictors from the preliminary models. Readiness for Hospital Discharge Scale, QDTS content difference, and feeding method as predictor variables together explained $25 \%$ of the variance in PDCDS with RHDS as the only significant independent predictor. The negative direction of the relationship between RHDS and PDCDS indicated that women who felt less ready for discharge reported greater coping difficulty in the first 3 weeks after discharge.

To determine if RHDS was predictive of postdischarge utilization of services, logistic regression analyses were conducted with each utilization variable as the outcome variable. Readiness for Hospital Discharge Scale scores were not predictive of any utilization variable.

\section{Additional Analyses}

9 Weiss \& Lokken 
To identify if the relationship of RHDS to utilization was indirect through its association with postdischarge coping, PDCDS scores were entered as a predictor variable for each utilization variable. Greater coping difficulty in the postdischarge period was associated with more call to friends and family for advice and support. All other variables antecedent to utilization in the study model were similarly entered in their transition model groupings in logistic regression analyses of predictors of utilization. The significant predictors of the utilization variables are detailed in Table 5. Younger mothers with a public payor source for health care were more likely to make calls to pediatric providers, but these mothers with public health care coverage were less likely to attend routine follow-up care for their newborns. Cesarean birth mothers were more likely to have routine and nonroutine office or clinic visits with their obstetric provider in the postdischarge period. This finding is consistent with recommendations for a followup visit for Cesarean mothers within 7 to 14 days postdelivery (AAP/ACOG, 2007) and with higher postpartum complication rates among Cesarean mothers (Borders, 2006; Miesnik \& Reale, 2007). Poor quality delivery of discharge teaching was associated with greater likelihood of newborn emergency or urgent care visits.

Figure 1 displays the significant predictors and outcomes of readiness for hospital discharge after birth identified from the analyses.

\section{Discussion}

The perception of readiness for discharge after birth involves a complex integration of perceptions about the birth mother's own physical status, knowledge about how to care for oneself and baby at home, a projection about one's ability to cope with family care needs at home, and the expectation of help and support in the initial transition period. Among the mothers in this study sample, none of the patient characteristics or birth hospitalization factors was predictive of mothers' perceptions of readiness for discharge, suggesting that readiness for discharge is a unique experience for each birth mother. As expected, most postpartum mothers reported being ready for discharge on their planned day of discharge. This finding is consistent with prior studies of postpartum mothers and other patient populations (Bernstein et al., 2002; Greene, 1991; Schaefer, Anderson, \& Simms, 1990; Weiss, Ryan, Lokken, \& Nelson, 2004; Weiss et al., 2006).

For this study, discharge teaching was characterized as the composite of all discharge-related teaching and patients were asked to report on the amount and quality of the teaching provided to them in preparation for going home. Overall, the mothers reported high-quality teaching in amounts in excess of their need. The quality of discharge teaching, both the amount of information received in excess of need and the way the nurses taught, were 
independently predictive of mothers' perceptions of their readiness for discharge. The greater the difference between need and received content and the greater the nurses' skill in delivering the information, the more ready the mother perceived herself to be for discharge. In the information age, the focus of teaching is often on content. Clearly the skill of the nurse in delivering preparatory information for the transition home needs as much emphasis as the content in the design of patient education programming and the professional development of the nursing staff. The elements of skilled discharge teaching as measured by the QDTS provide a guide for skill building. The results demonstrate the value-added of content presented in excess of the mother's stated need. Mothers may not recognize the scope of their learning needs during the intense period of recovery and reorganization following birth. The intensity of teaching and the skilled delivery of postpartum teaching have benefits that become evident in the ability of new mothers to cope with self, infant, and family needs after discharge home.

How important is it for postpartum mothers to feel ready to go home? The mothers in this study all had essentially normal postpartum courses and were discharged home with their normal newborns. They completed the RHDS after they were deemed ready for discharge by both the obstetric and pediatric provider and informed they were being discharged. Yet those who felt less ready for discharge had greater difficulty coping at home, which resulted in more frequent calls to friends and family for advice and support. Those who felt they received poorer quality of delivery of the discharge teaching had more urgent care/emergency visits for newborn problems. The mothers chose urgent/emergency level services for these self-identified problems. No information was available about the clinician's assessment of the urgency of the newborn problems. A prior study conducted the same study site revealed an association between discharge readiness and fewer unscheduled contacts with providers (Weiss et al., 2006). Assessment of maternal perceptions of lack of readiness throughout the course of the childbirth hospitalization will assist in identifying mothers at risk for difficulty in coping at home following discharge at a time when anticipatory interventions could effectively promote an easier transition. As a core postpartum nursing practice, incorporating discharge teaching into all patient encounters will provide multiple opportunities to reinforce discharge preparatory content and promote the mother's feelings of competence and confidence in her readiness to take on the roles of self, infant, and family care at home.

The trajectory of influence in this study suggests that both the content amount and delivery skill aspects of quality of discharge teaching are associated with readiness for discharge, which is then associated with lower postdischarge coping difficulty and lower utilization of support from

\section{Weiss \& Lokken}


family and friends. These results provide evidence of the importance of discharge readiness as an intermediate outcome in the childbirth discharge transition. The findings support the constructs and relationships proposed by Transitions Theory. The impact of discharge teaching as a nursing therapeutic intervention was evident in the transitional outcomes at the time of discharge and remote from discharge after the mother and newborn have experienced the challenges of postpartum self and infant management at home. The nature of the transition (birth hospitalization factors) and the transition conditions (patient characteristics) were associated with the patterns of response in the post-discharge period. The theory provides a useful guiding framework for research about transitional situations and for patient assessment and measurement of outcomes.

\section{Limitations}

The data sources for this study were postpartum mothers' reports of their perceptions about their discharge transition, including perceptions of the discharge teaching, readiness for discharge, postdischarge coping difficulty, and self-reports of service utilization. These perceptions reflected the mothers' realities but may not represent the clinical reality or the actual teaching that was provided. Nurses' and physicians' assessments of discharge readiness and documentation of discharge teaching delivered by the nurse may be different than that perceived by the patient. The relationship between patient and provider perspectives was not investigated in this study. Further exploration to determine the relative contribution of patient, nurse, and physician assessments of discharge readiness to postdischarge outcomes would provide valuable knowledge for decision-making about discharge readiness and activation of postdischarge services.

Data for this study were collected from mothers experiencing uncomplicated births in a single hospital and therefore may not reflect the experience of patients in other facilities, locations, types of birthing centers, or with complicated birth or postpartum experiences. The instruments for the study were developed for the specific purposes of the three study concurrent series, of which this study was a part. Reliability estimates were acceptable and validity was supported in each of the three studies. These instruments will benefit from additional testing in other settings. The number of subjects was adequate for the number of variables entered into the multiple regression equations, providing sufficient power for analyses of readiness for discharge and postdischarge coping. However, for utilization variables such as urgent care and emergency visits that are infrequent occurrences among healthy postpartum women, more subjects are needed to confidently explore the relationships with predictor variables.

12 Weiss \& Lokken 


\section{Conclusions}

The trajectory of sequential influence from quality of discharge teaching to readiness for discharge, postdischarge coping, and utilization of family support and health care services provides evidence of the critical role of postpartum teaching in promoting proximal and distal maternal-neonatal outcomes. New mothers feel ready for discharge when they feel physically capable, knowledgeable, confident in their ability to cope with caring for themselves, their newborns, and their families at home, and supported by those around them. Both the amount of content provided to new mothers and the skill of nurses in delivering discharge informational content are associated with new mothers' readiness for hospital discharge. Level of readiness is associated with postdischarge coping difficulty and utilization of family supports. Discharge teaching provided throughout the postpartum hospitalization is an anticipatory intervention that requires attention to adequacy of content and delivery using teaching approaches that will facilitate translation of content to health-promoting self and infant care behaviors at home. Efforts to improve discharge teaching and its outcomes should focus on improvement of the quality of content and delivery through organized initiatives to assure content delivery by skilled nurse teachers.

This study has documented the importance of the patient's perspective in assessments of discharge readiness. Patient perception of discharge readiness can be both a process measure to identify patients in need of additional interventions before and after discharge and a nurse-sensitive outcome measure of the postpartum hospitalization experience. Assessment of the quality of discharge teaching and readiness for discharge should be part of discharge preparation for every patient. These assessments provide a window for nurses to view patients' perceptions of the process and outcomes of the discharge preparation. Mothers whose self-assessments reveal a low level of discharge readiness may benefit from rescue strategies to avert adverse outcomes. These strategies might include reinforcement of teaching before discharge, engaging family members for postdischarge support, or arranging postdischarge surveillance and continuation of teaching by home health services. Building systems of care that routinely assess discharge preparation and discharge readiness will promote optimal short- and long-term outcomes of the postchildbirth experience. Transitions theory, a nursing theory that incorporates the patient's experience and the role of the nurse, was a useful framework in developing the investigation of the childbirth discharge transition and could be equally as useful for planning systems of care that address the important transitional process and outcomes for new families.

13 Weiss \& Lokken 


\section{Acknowledgments}

- The authors thank Marquette University College of Nursing undergraduate nursing student research assistants Janet Barnes, Teresa Jerofke, Emily Moore, and Robyn Yourell.

\section{Notes}

- Correspondence:

Marianne E. Weiss, RN, DNSc, Marquette University College of Nursing, PO Box 1881, Milwaukee, WI, 53201-1881 Marianne.weiss@marquette.edu

- Marianne E. Weiss, RN, DNSc is an associate professor and Wheaton Franciscan Healthcare-St. Joseph/Sister Rosalie Klein professor of Women's Health in the College of Nursing, Marquette University, Milwaukee, WI.

- Lisa Lokken, RNC, MSN, RNC, is a perinatal clinical nurse specialist at Wheaton Franciscan Healthcare-St. Joseph, Milwaukee WI.

\section{References}

American Academy of Pediatrics/American College of Obstetricians and Gynecologists (2007). Guidelines for perinatal care (6th ed.). Elk Grove Village, IL: Authors.

Beger, D., \& Cook, C. A. L. (1998). Postpartum teaching priorities: The viewpoints of nurses and mothers. Journal of Obstetric, Gynecologic, \& Neonatal Nursing, 27,161-168.

Bernstein, H. H., Spino, C., Baker, A., Slora, E. J., Touloukian, C. L., \& McCormick, M. C. (2002). Postpartum discharge: Do varying perceptions of readiness impact health outcomes? Ambulatory Pediatrics, 2(5), 388-395.

Borders, N. (2006). After the afterbirth: A critical review of postpartum health relative to method of delivery. Journal of Midwifery and Women's Health, 51(4), 242-248.

Bowman, K. G. (2005). Postpartum learning needs. Journal of Obstetric, Gynecologic, \& Neonatal Nursing, 34, 438-443.

Greene, M. (1991). Adult surgical patients' perceptions of discharge readiness and postoperative recovery. Unpublished master's thesis, University of Wisconsin-Milwaukee, Milwaukee, WI.

Hollingshead, A. (1975). Four factor index of social status (working paper). New Haven, CT: Hollingshead.

Meleis, A. I., Sawyer, L. M., Im, E.-O., Messias, D. K., \& Schumacher, K. (2000). Experiencing

14 Weiss \& Lokken 
transitions: An emerging middle-range theory. Advances in Nursing Science, 23(1), 12-28.

Meleis, A. I., \& Trangenstein, P. A. (1994). Facilitating transitions: Redefinition of the nursing mission. Nursing Outlook, 42, 255-259.

Miesnik, S. R., \& Reale, B. J. (2007). A review of issues surrounding medically elective Cesarean delivery. Journal of Obstetric, Gynecologic, \& Neonatal Nursing, 36(6), 605-615.

Polit, D. F. (1996). Data analysis \& statistics for nursing research. Upper Saddle River, NJ: Prentice Hall.

Ruchala, P. L. (2000). Teaching new mothers: Priorities of nurses and postpartum women. Journal of Obstetric, Gynecologic, \& Neonatal Nursing, 29(3), 265-273.

Schaefer, A. L., Anderson, J. E., \& Simms, L. M. (1990). Are they ready? Discharge planning for older surgical patients. Journal of Gerontological Nursing, 16(10), 16-19.

Sword, W., \& Watt, S. (2005).Learning needs of postpartum women: Does socioeconomic status matter. Birth, 32, 86-92.

Titler, M. G., \& Pettit, D. M. (1995). Discharge readiness assessment. Journal of Cardiovascular Nursing, 9(4), 64-74.

Weiss, M., Johnson, N., Malin, S., Jerofke, T., Lang, C., \& Sherburne, E. (2008). Readiness for discharge in parents of hospitalized children. Readiness for discharge in parents of hospitalized children. Journal of Pediatric Nursing, 23(4), 282-295.

Weiss, M., Piacentine, L., Lokken, L., et al. (2007). Perceived readiness for hospital discharge in adult medical-surgical patients. Clinical Nurse Specialist, 21(1), 31-42.

Weiss, M., Ryan, P., \& Lokken, L. (2006). Validity and reliability of the Perceived Readiness For Discharge After Birth Scale. Journal of Obstetric, Gynecologic, \& Neonatal Nursing, 35(1), 34-45.

Weiss, M., Ryan, P., Lokken, L., \& Nelson, M. (2004). Length of stay after vaginal birth: Sociodemographic and readiness-for-discharge factors. Birth, 31(2), 93-101.

Weiss, M. E., \& Piacentine, L. B. (2006). Psychometric properties of the Readiness for Hospital Discharge Scale. Journal of Nursing Measurement, 14(3), 163-180. 


\section{Appendix}

Table 1

Sociodemographic Characteristics of the Study Sample

\begin{tabular}{|c|c|c|}
\hline & \multicolumn{2}{|c|}{ Postpartum, $n=141^{\mathrm{a}}$} \\
\hline Sociodemographic Characteristics & Mean & $S D$ \\
\hline Age & 28.6 & 6.2 \\
\hline \multirow{2}{*}{ Socioeconomic status ${ }^{b}$} & 43.6 & 15.9 \\
\hline & No. & $\%$ \\
\hline \multicolumn{3}{|l|}{ Race } \\
\hline White & 74 & 53.2 \\
\hline Black & 45 & 32.4 \\
\hline Hispanic & 7 & 5.0 \\
\hline Asian & 7 & 5.0 \\
\hline Other & 6 & 4.3 \\
\hline \multicolumn{3}{|l|}{ Living with father of baby } \\
\hline \multicolumn{3}{|l|}{ Yes } \\
\hline Married & 86 & 64.2 \\
\hline Single & 28 & 20.9 \\
\hline No & 20 & 14.9 \\
\hline \multicolumn{3}{|l|}{ Education } \\
\hline Less than high school & 14 & 10.3 \\
\hline High school & 32 & 23.5 \\
\hline Partial college ( $\geq 1$ year) & 35 & 25.7 \\
\hline 4 years of college & 39 & 28.7 \\
\hline Graduate education & 16 & 11.8 \\
\hline \multicolumn{3}{|l|}{ Payor } \\
\hline Public & 33 & 23.6 \\
\hline Private & 107 & 76.4 \\
\hline \multicolumn{3}{|l|}{ Parity } \\
\hline Primipara & 54 & 39.4 \\
\hline Multipara & 83 & 60.6 \\
\hline \multicolumn{3}{|l|}{ Type of delivery } \\
\hline Vaginal & 100 & 70.9 \\
\hline Cesarean & 41 & 29.1 \\
\hline \multicolumn{3}{|l|}{ Feeding } \\
\hline Breast & 94 & 68.1 \\
\hline Bottle & 44 & 31.9 \\
\hline
\end{tabular}

Note. ${ }^{2}$ Some categories do not total the reported $n$ due to missing data.

${ }^{b}$ Hollingshead (1975) Four Factor Index of Social Status 


\section{Table 2}

Summary of Predictor and Outcome Measures

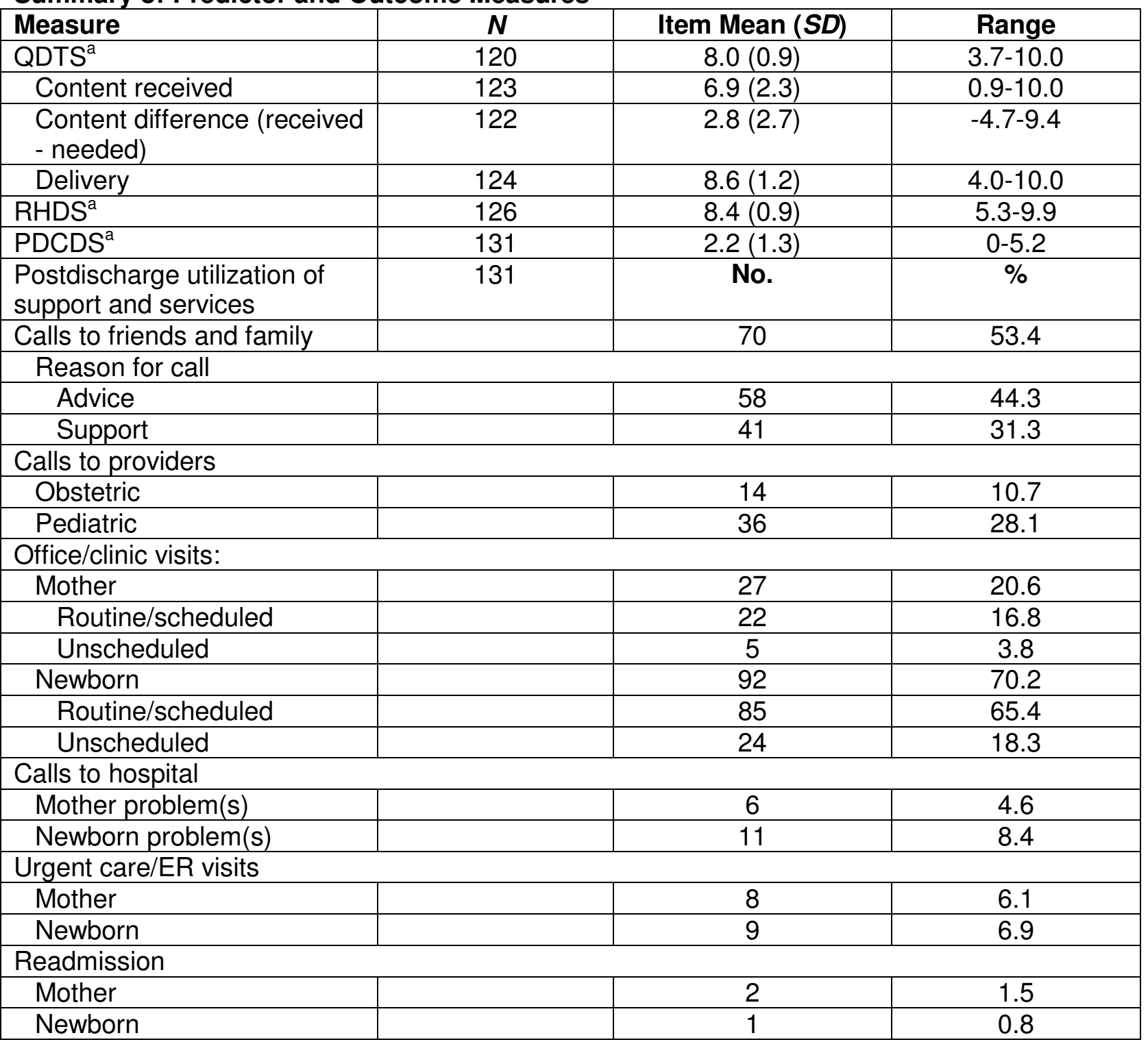

Note. ER = Emergency room; PDCDS = Post-Discharge Coping Difficulty Scale; QDTS = Quality of Discharge Teaching Scale; RHDS = Readiness for Hospital Discharge Scale

${ }^{a}$ QDTS, RHDS, and PDCDS use 0 to 10 point scales. 
Table 3

Predictors of Readiness for Hospital Discharge Scale

\begin{tabular}{|c|c|c|c|c|c|c|}
\hline \multirow{2}{*}{$\begin{array}{l}\text { Nursing Practice } \\
\text { Predictor Variables }\end{array}$} & \multirow{2}{*}{ Model Statistics } & \multicolumn{5}{|c|}{$\begin{array}{r}\text { Variable Statistics } \\
\end{array}$} \\
\hline & & $B$ & $S E B$ & $\begin{array}{c}\text { Standardized } \\
\beta\end{array}$ & $t$ & $P$ \\
\hline \multirow{4}{*}{$\begin{array}{l}\text { Model 1: Patient } \\
\text { characteristic (age, } \\
\text { race, socioeconomic } \\
\text { status, living with } \\
\text { father of baby, } \\
\text { payor) }\end{array}$} & $F(5,53)=2.17$ & & & & & $n s$ \\
\hline & $p=0.06$ & & & & & \\
\hline & $R^{2}=0.10$ & & & & & \\
\hline & $\begin{array}{l}\text { Adjusted } R^{2}= \\
0.06\end{array}$ & & & & & \\
\hline \multirow{4}{*}{$\begin{array}{l}\text { Model 2: } \\
\text { Hospitalization } \\
\text { factors (prior birth, } \\
\text { type of delivery, } \\
\text { feeding method) }\end{array}$} & $F(3,117)=1.39$ & & & & & \\
\hline & $p=0.25$ & & & & & ns \\
\hline & $R^{2}=0.03$ & & & & & \\
\hline & $\begin{array}{l}\text { Adjusted } R^{2}= \\
0.01\end{array}$ & & & & & \\
\hline \multirow{4}{*}{$\begin{array}{l}\text { Model 3a: Nurse } \\
\text { practice } \\
\text { (a) QDTS total } \\
\text { (content } \\
\text { received + } \\
\text { delivery } \\
\text { subscales) }\end{array}$} & $F(1,118)=21.22$ & & & & & \\
\hline & $p<0.001$ & .32 & .07 & .39 & 4.61 & $<.001$ \\
\hline & $R^{2}=0.15$ & & & & & \\
\hline & $\begin{array}{l}\text { Adjusted } R^{2}= \\
0.15\end{array}$ & & & & & \\
\hline \multirow{4}{*}{$\begin{array}{l}\text { Model 3b: Nurse } \\
\text { Practice } \\
\text { (a) QDTS received } \\
\text { subscale } \\
\text { (b) QDTS delivery } \\
\text { subscale }\end{array}$} & $F(2,117)=13.84$ & .07 & .13 & .05 & 0.51 & .61 \\
\hline & $p<0.001$ & .61 & .14 & .41 & 4.39 & $<.001$ \\
\hline & $R^{2}=0.19$ & & & & & \\
\hline & $\begin{array}{l}\text { Adjusted } R^{2}= \\
0.18\end{array}$ & & & & & \\
\hline \multirow{4}{*}{$\begin{array}{l}\text { Model 3c: Nurse } \\
\text { practice } \\
\text { (a) QDTS content } \\
\text { difference } \\
\text { subscale } \\
\text { (b) QDTS delivery } \\
\text { subscale }\end{array}$} & $F(2,116)=35.71$ & .52 & .09 & .47 & 6.00 & $<.001$ \\
\hline & $p<0.001$ & .38 & .12 & .26 & 3.27 & .001 \\
\hline & $R^{2}=0.38$ & & & & & \\
\hline & $\begin{array}{l}\text { Adjusted } R^{2}= \\
0.37\end{array}$ & & & & & \\
\hline
\end{tabular}

Note. QDTS = Quality of Discharge Teaching Scale.

18 Weiss \& Lokken 
Table 4

Predictors of Postdischarge Coping Difficulty Scale

\begin{tabular}{|c|c|c|c|c|c|c|}
\hline & 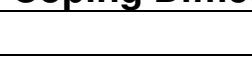 & & & riable Statistic & & \\
\hline Predictor Variables & $\begin{array}{c}\text { Model } \\
\text { Statistics }\end{array}$ & $B$ & SE B & $\underset{\beta}{\text { Standardized }}$ & $t$ & $P$ \\
\hline Model 1: RHDS & $\begin{array}{c}F(1,114)= \\
32.44\end{array}$ & -0.28 & 0.05 & -.47 & -5.70 & $<.001$ \\
\hline & $p<0.001$ & & & & & \\
\hline & $R^{2}=0.22$ & & & & & \\
\hline & $\begin{array}{c}\text { Adjusted } R^{2}= \\
0.22\end{array}$ & & & & & \\
\hline Model 2: Patient & $F(5,97)=2.90$ & & & & & ns \\
\hline characteristics: & $p=0.01$ & & & & & \\
\hline (age, race, socioeconomic & $R^{2}=0.16$ & & & & & \\
\hline $\begin{array}{l}\text { status, living with father of } \\
\text { baby, payor) }\end{array}$ & $\begin{array}{c}\text { Adjusted } R^{2}= \\
0.10\end{array}$ & & & & & \\
\hline $\begin{array}{l}\text { Model 3: Hospitalization } \\
\text { factors }\end{array}$ & $\begin{array}{c}F(3,124)= \\
3.24\end{array}$ & & & & & \\
\hline Prior birth: $0=$ primipara, $1=$ & $p=0.01$ & -2.52 & 2.23 & -.10 & -1.13 & .26 \\
\hline multipara & $R^{2}=0.10$ & 4.31 & 2.41 & .16 & 1.79 & .08 \\
\hline $\begin{array}{l}\text { Type of delivery: } 0=\text { vaginal, } \\
1=\text { Cesarean } \\
\text { Feeding method: } 0=\text { bottle, } 1 \\
\text { = breast }\end{array}$ & $\begin{array}{c}\text { Adjusted } R^{2}= \\
0.07\end{array}$ & 5.12 & 2.40 & .21 & 2.46 & .02 \\
\hline $\begin{array}{l}\text { Model 4a: Nurse practice } \\
\text { (a) QDTS total (content }\end{array}$ & $\begin{array}{c}F(1,111)= \\
2.45\end{array}$ & & & & & ns \\
\hline received + delivery) & $p=0.12$ & & & & & \\
\hline & $R^{2}=0.02$ & & & & & \\
\hline & $\begin{array}{c}\text { Adjusted } R^{2}= \\
0.01\end{array}$ & & & & & \\
\hline $\begin{array}{l}\text { Model 4b: Nurse practice } \\
\text { (a) QDTS content }\end{array}$ & $\begin{array}{c}F(2,110)= \\
2.59\end{array}$ & & & & & ns \\
\hline received subscales & $p=0.08$ & & & & & \\
\hline (b) QDTS delivery & $R^{2}=0.05$ & & & & & \\
\hline subscales & $\begin{array}{c}\text { Adjusted } R^{2}= \\
0.03\end{array}$ & & & & & \\
\hline $\begin{array}{l}\text { Model 4c: Nurse practice } \\
\text { (a) QDTS-Content }\end{array}$ & $\begin{array}{c}F(2,109)= \\
7.30\end{array}$ & & & & & \\
\hline difference subscale & $p=0.001$ & -0.20 & 0.07 & -0.30 & -3.08 & .003 \\
\hline (b) QDTS-Delivery & $R^{2}=0.12$ & & & & & \\
\hline & $\begin{array}{c}\text { Adjusted } R^{2}= \\
0.10\end{array}$ & -0.08 & 0.09 & -0.09 & -0.96 & .34 \\
\hline $\begin{array}{l}\text { Model 5: All significant } \\
\text { predictors }\end{array}$ & $\begin{array}{c}F(3,108)= \\
11.69\end{array}$ & & & & & \\
\hline (a) RHDS & $p<0.001$ & -.24 & 0.06 & -0.41 & -4.03 & $<.001$ \\
\hline (b) QDTS-Content & $R^{2}=0.25$ & -0.07 & 0.07 & -0.10 & -0.93 & .35 \\
\hline $\begin{array}{l}\text { difference } \\
\text { (c) Feeding method: } 0= \\
\text { bottle, } 1=\text { breast }\end{array}$ & $\begin{array}{c}\text { Adjusted } R^{2}= \\
0.22\end{array}$ & 3.99 & 2.29 & 0.15 & 1.77 & .08 \\
\hline
\end{tabular}

Note. QDTS = Quality of Discharge Teaching Scale; RHDS = Readiness for Hospital Discharge Scale

19 Weiss \& Lokken 
Table 5

Significant Predictors of Postdischarge Utilization

\begin{tabular}{|c|c|c|c|c|c|c|c|}
\hline \multirow{2}{*}{\begin{tabular}{l|l} 
& \\
Outcome \\
Variables
\end{tabular}} & \multirow{2}{*}{$\begin{array}{l}\text { Significant } \\
\text { Predictor } \\
\text { Variables }\end{array}$} & \multicolumn{6}{|c|}{ Logistic Regression Statistics } \\
\hline & & $B$ & $S E$ & $x^{2}$ & $\begin{array}{l}\text { Odds } \\
\text { Ratio }\end{array}$ & $95 \% \mathrm{Cl}$ & $\boldsymbol{P}$ \\
\hline $\begin{array}{l}\text { Calls to family and } \\
\text { friends }\end{array}$ & PDCDS & 0.09 & 0.02 & 22.01 & 1.09 & $1.05-1.13$ & $<.001$ \\
\hline $\begin{array}{l}\text { Calls to obstetric } \\
\text { provider }\end{array}$ & & & & & & & ns \\
\hline \multirow{2}{*}{$\begin{array}{l}\text { Calls to pediatric } \\
\text { provider }\end{array}$} & Age & -0.17 & 0.06 & 7.43 & 0.85 & $0.75-0.95$ & .01 \\
\hline & $\begin{array}{l}\text { Payor }(0= \\
\text { public, } 1= \\
\text { private })\end{array}$ & -1.94 & 0.74 & 6.81 & 0.14 & $0.03-0.62$ & .01 \\
\hline $\begin{array}{l}\text { Calls to hospital for } \\
\text { mother problems }\end{array}$ & & & & & & & $n s$ \\
\hline $\begin{array}{l}\text { Calls to hospital for } \\
\text { newborn problems }\end{array}$ & & & & & & & ns \\
\hline \multicolumn{8}{|l|}{ Office visits-maternal } \\
\hline Total & $\begin{array}{l}\text { Type of birth } \\
(0=\text { vaginal, } \\
1= \\
\text { Cesarean })\end{array}$ & 1.67 & 0.46 & 13.44 & 5.36 & $2.18-13.18$ & $<.001$ \\
\hline Routine/scheduled & Type of birth & 1.33 & 0.48 & 7.57 & 3.79 & $1.47-9.77$ & .01 \\
\hline Non-routine & Type of birth & 2.37 & 1.14 & 4.36 & 10.71 & $1.16-99.21$ & .04 \\
\hline \multicolumn{8}{|c|}{ Office/clinical visits-newborn } \\
\hline Total & $\begin{array}{l}\text { Payor }(0= \\
\text { public, } 1= \\
\text { private })\end{array}$ & 1.24 & 0.49 & 6.54 & 3.46 & $2.34-8.97$ & .01 \\
\hline Routine/scheduled & Payor & 1.54 & 0.45 & 11.93 & 4.66 & $1.95-11.15$ & .001 \\
\hline Non-routine & & & & & & & $n s$ \\
\hline $\begin{array}{l}\text { Urgent care/ER } \\
\text { visits-mother }\end{array}$ & & & & & & & $n s$ \\
\hline $\begin{array}{l}\text { Urgent care/ER } \\
\text { visits-baby }\end{array}$ & $\begin{array}{l}\text { QDTS- } \\
\text { delivery }\end{array}$ & -0.64 & 0.30 & 4.62 & 0.53 & $0.30-0.95$ & .03 \\
\hline
\end{tabular}

Note. ER = emergency room; PDCDS = Post-Discharge Coping Difficulty Scale; QDTS = Quality of

Discharge Teaching Scale 
Figure 1

Predictors and outcomes of readiness for hospital discharge after birth.

Nursing Therapeutics

Patterns of Response

Discharge Teaching

- Content difference

\section{Discharge Postdischarge}

- Delivery

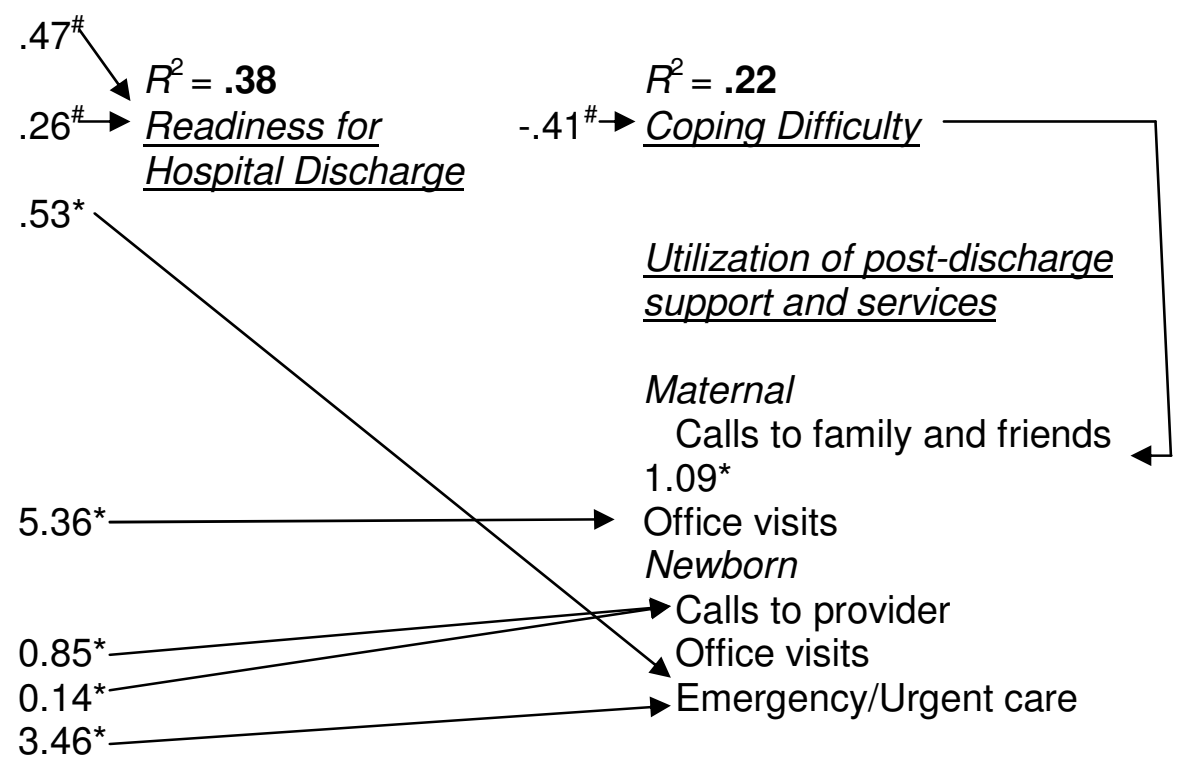

\#Standardized b; *odds ratio

21 Weiss \& Lokken 